\title{
Thiamine and diabetes: back to the future?
}

\author{
Elena Beltramo ${ }^{1}\left[\right.$. Aurora Mazzeo ${ }^{1} \cdot$ Massimo Porta $^{1}$
}

Received: 10 May 2021 / Accepted: 26 May 2021 / Published online: 5 June 2021

(c) The Author(s) 2021

\begin{abstract}
The first reports of a link between thiamine and diabetes date back to the 1940s. Some years later, a role for thiamine deficiency in diabetic neuropathy became evident, and some pilot studies evaluated the putative effects of thiamine supplementation. However, the administration of thiamine and its lipophilic derivative benfotiamine for the treatment of this complication gained consensus only at the end of the ' $90 \mathrm{~s}$. The first evidence of the beneficial effects of thiamine on microvascular cells involved in diabetic complications dates to 1996: from then on, several papers based on in vitro and animal models have addressed the potential use of this vitamin in counteracting diabetic microangiopathy. A few pilot studies in humans reported beneficial effects of thiamine administration on diabetic nephropathy, but, despite all promising proofs-of-concept, the possible role of thiamine in counteracting development or progression of retinopathy has not been addressed until now. Thiamine is a water-soluble vitamin, rapidly expelled from the body, with no issues of over-dosage or accumulation; unfortunately, it is non-patentable, and neither industry nor independent donors are interested in investing in large-scale randomized controlled clinical trials to investigate its potential in diabetes and its complications. Consequently, science will not be able to disprove a promising hypothesis and, more importantly, diabetic people remain deprived of a possible way to ameliorate their condition.
\end{abstract}

Keywords Thiamine $\cdot$ Benfotiamine $\cdot$ Diabetes $\cdot$ Diabetic retinopathy $\cdot$ Diabetic nephropathy $\cdot$ Diabetic neuropathy

\author{
Abbreviations \\ AGE Advanced glycation-end products \\ HIF-1 $\alpha \quad$ Hypoxia-inducible factor- $1 \alpha$ \\ TDP Thiamine diphosphate \\ THTR1 Thiamine transporter-1 \\ THTR2 Thiamine transporter-2 \\ TK Transketolase \\ TRMA Thiamine-responsive megaloblastic anaemia \\ RCT Randomized controlled clinical trial \\ ROS Reactive oxygen species \\ VEGF Vascular endothelial growth factor
}

"I think that experiments with vitamins, which can at least do no harm, ought to be performed here in order

Managed by Massimo Federici.

Elena Beltramo

elena.beltramo@unito.it

1 Dept. Medical Sciences, University of Torino, Corso AM Dogliotti 14, 10126 Torino, Italy to ascertain if a deficiency of the latter is not the real primary cause of the disease" Funk C, 1922 [1]

"In clinical trials of vitamin B1 (thiamin) in cases of diabetes the author, during the past few years, has found that administration of thiamin, either parenterally or orally, effects some improvement in the carbohydrate tolerance of the diabetic patient and has further observed an apparent economy of insulin in several instances after its administration" Bose JP, 1949 [2]

\section{The first vitamin}

Thiamine (vitamin B1) is a water-soluble vitamin belonging to the B group, the first to be isolated in 1926 [3]. As all water-soluble vitamins, it is rapidly expelled through the urinary system, does not accumulate in the body, and has no toxic effects. Nevertheless, it is an essential cofactor of glucose metabolism in almost all living organisms and a modulator of neuronal and neuro-muscular transmission in vertebrates [4]. Small amounts of it need to be assumed frequently with the diet [5]. Thiamine deficiency causes severe disorders, especially linked to the nervous system (beriberi, 
Wernicke-Korsakoff syndrome) [3, 6], which were once very frequent in people on poor, unvaried diets, lacking in whole grains, meat, legumes, and nuts, and easily resolved by thiamine assumption. Alcoholics are often thiamine deficient, mainly because of the impairing effects of chronic alcohol intake on intestinal absorptive mechanisms [7]. Low thiamine levels are often associated also with diabetes [8].

Absorption of thiamine is mainly mediated by two highly specific transporters, THTR 1 and THTR2, largely present in almost all tissues [9]. At high concentrations, chiefly after pharmacological assumption, passive diffusion may also occur [10]. Once inside the cell, thiamine is phosphorylated to its active form, thiamine diphosphate (TDP), a cofactor for several enzymes involved mainly in glucose metabolism. These include: (1) transketolase (TK), which shifts excess glyceraldehyde-3-phosphate and fructose-6-phosphate from glycolysis toward the pentose phosphate shunt, thus eliminating highly reactive toxic metabolites from the cytoplasm; (2) the pyruvate-dehydrogenase complex, responsible for oxidative decarboxylation of pyruvate, the final product of glycolysis, to acetyl-CoA, which then enters the Krebs cycle; and (3) $\alpha$-keto-glutarate-dehydrogenase, which facilitates the flow through the Krebs cycle (Fig. 1).
Genetic defects in intracellular thiamine transport are responsible for severe systemic disorders. Thiamine-responsive megaloblastic anemia (TRMA), a rare syndrome characterized by diabetes, anemia, and sensorineural deafness was described in 1978 [11], and later associated with a defect in the SLC19A2 gene encoding for thiamine transporter-1 (THTR1) [12]. Since THTR1 is the only transporter of thiamine into pancreatic $\beta$-cells, cochlear cells, hemopoietic tissues and retinal pigment epithelial cells, its deficiency leads to cell apoptosis and organ failure [10]. Mutations in the SLC19A3 gene encoding for thiamine transporter-2 (THTR2) are responsible for biotin-responsive basal ganglial disease [13] and thiamine-responsive encephalopathy [14].

A group of lipid-soluble thiamine derivatives, with higher absorption and bioavailability than water-soluble thiamine salts, was isolated in the 1960s [15]. Among these, one of the most effective is benfotiamine, which was specifically developed to improve bioavailability for oral administration $[16,17]$, and is currently marketed in some countries as an over-the-counter drug for the treatment of diabetic neuropathy.

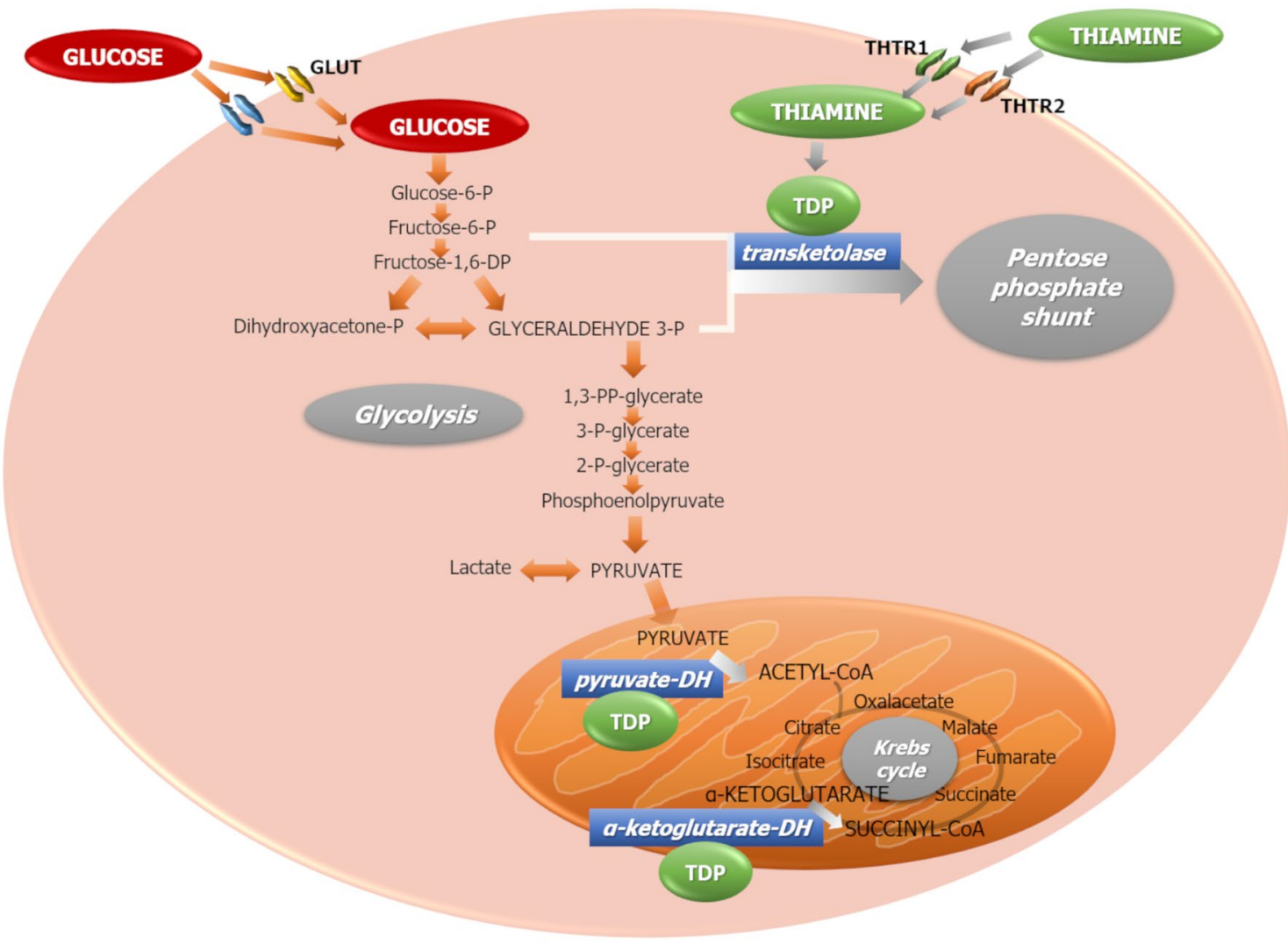

Fig. 1 Thiamine enters the cells via thiamine transporters 1 (THTR1) and 2 (THTR2). Inside the cytoplasm, it is phosphorylated to its active form, thiamine diphosphate (TDP), an essential cofactor for several enzymes involved in glycolysis and Krebs cycle. Particularly important are transketolase, pyruvate-dehydrogenase and $\alpha$-ketoglutarate-dehydrogenase. GLUT: glucose transporters 


\section{A brief history of thiamine and diabetes}

A research on PubMed using the MeSH terms "thiamine" AND "diabetes" permits to date back to 1947 the first official report of a link between this vitamin and diabetes: that paper described thiamine deficiency in diabetic as compared to healthy rats [18]. However, proof of this association had been already published previously, though not listed in PubMed: two studies in 1940 described deficiency of cocarboxylase (i.e., thiamine diphosphate, TDP) in diabetic patients $[19,20]$, and were confirmed by subsequent observations [21]. In 1948, a British medical officer stationed in India reported on the reduction in glycemia and glycosuria in a group of diabetic subjects treated with $50 \mathrm{mg}$ of daily intramuscular thiamine chloride for 10-14 days; thiamine administration also reduced the need for insulin in insulintreated patients [2]. One year later, Markees and Meyer [22] reported on the beneficial effects of the administration of cocarboxylase in diabetic coma, and a debate on this topic arose in the following decade. Several subsequent reports postulated a synergic action of insulin and cocarboxylase in the treatment of diabetic coma and indicated as a putative mechanism of action the reduction of pyruvic acid, increased in decompensated diabetic patients [23-26]. The positive effects of thiamine and its phosphorylated forms on glycemia and glycosuria, already reported by Bose in 1948, were confirmed in the ' $50 \mathrm{~s}[27,28]$. Those reports leant toward a stronger effect of cocarboxylase rather than thiamine itself. However, soon after, administration of thiamine hydrochloride gained major credit because, while TDP cannot enter the cells directly, the free form of thiamine is recognized by its transporters and then phosphorylated to active TDP only inside the cytoplasm [26].

Unfortunately, after this rise of interest in the ' 50 s, the potential of thiamine and its derivatives in the treatment of diabetes started to lose appeal. More than thirty years later, a new study evidenced thiamine deficiency in diabetic subjects [29], and confirming reports were published in the subsequent decades [30-33]. But, after the pioneering studies of the ' $50 \mathrm{~s}$, no further attempts to ameliorate the diabetic condition through the administration of thiamine were described until the dawn of the new millennium, when some studies reported on small groups of patients supplemented with vitamin B1 or one of its derivatives (benfotiamine, benzoyloxymethyl-thiamine). Valerio et al. [34] found no differences in HbA1c in type 1 diabetic children after 3-month treatment with benzoyloxymethyl-thiamine, while a group of type 2 diabetic patients experienced improved endothelial function and reduced development and progression of atherosclerosis after intravenous injection of thiamine [35]. Benfotiamine was shown to prevent macro- and micro-vascular endothelial dysfunction and oxidative stress following a meal rich in advanced glycation end products [36], and to ameliorate erythrocyte transketolase activity in type 2 diabetic patients [31]. One-month thiamine administration decreased glycemia and leptin concentrations in subjects with type 2 diabetes [37], and improvements were described in glucose tolerance [38] and blood pressure [39] in subjects with hyperglycaemia, following high-dose thiamine supplementation. Gestational diabetes was also associated with thiamine mishandling [40]: in these women, thiamine supplementation reduced inflammatory and oxidative markers [41]. Unfortunately, these timid approaches were never followed by proper randomized controlled clinical trials (RCTs).

\section{Thiamine and diabetic neuropathy}

The literature is more abundant about thiamine treatment of diabetic neuropathy. The symptoms of a neurological and cardiovascular disease, later identified as beriberi, had been described in traditional Chinese medicine as far as the third century AD [42]. In 1897, the Dutch physician Christiaan Eijkman, sent to the Dutch East Indies to study beriberi, first linked this disorder to a poor diet (namely the assumption of polished rice) [43] and a few years later, in 1906, Hopkins hypothesized that food contains additional essential nutrients, apart from proteins, fat and carbohydrates [44]. Funk called these nutrients "vitamines", after coming to the conclusion that they should belong to the amine group and be necessary for life (the "e" was dropped when it was discovered that not all the vitamins were effectively amines) [1]. Eijkman and Hopkins were awarded the Nobel Prize in Physiology or Medicine in 1929 for their discoveries, which led to the isolation of thiamine by Jansen and Donath in 1926, and the association of beriberi with thiamine deficiency [3]. Lack of thiamine is also the cause of the Wernicke-Korsakoff syndrome, or cerebral beriberi, a neuropsychiatric disease described at the end of the nineteenth century and characterized by paralysis of eye movements, abnormal stance and gait, and deranged mental function [6]. Both syndromes are readily resolved by the administration of thiamine. Therefore, it was soon hypothesized that thiamine could be of help also for the treatment of diabetic neuropathy: the first hypothesis of such indication dates back to 1954 [45]. Eight years later, a review by Whitsell attests that thiamine chloride (as well as other vitamins belonging to the $\mathrm{B}$ group) has "been generously used in treatment [of diabetic neuropathy] with great enthusiasm in many reports" [46]. However, it was at the end of the "90s that the administration of thiamine and its lipophilic derivative benfotiamine in the treatment of this complication gained some consensus. Several subsequent reports confirmed that neuropathic symptoms and deficits, and nerve conduction velocity, were 
significantly improved by thiamine/benfotiamine administration in subjects with diabetic neuropathy [47-53].

\section{Thiamine and the microvascular complications of diabetes}

The first evidence of the beneficial effects of thiamine on cells involved in diabetic microvascular complications is much more recent. In 1996, La Selva and co-workers demonstrated that thiamine neutralizes the damaging effects of high glucose concentrations in cultured endothelial cells, lowering lactate production and advanced glycation-end product (AGE) formation, and preserving cell replication [54]. Since then, several papers addressed the potential of the vitamin in counteracting diabetic microangiopathy. Actually, the possible key role of thiamine in accelerating glucose metabolism and eliminating toxic metabolites is intuitive. Cells involved in diabetic retinopathy and nephropathy are insulin-independent and, consequently, more prone to glucose-induced damage. Highly reactive intermediates of glycolysis accumulate into the cytoplasm and accelerate the four metabolic pathways involved in glucose damage: polyol pathway, hexosamine pathway, de novo synthesis of protein kinase $\mathrm{C}$, and AGE formation, finally leading to the accumulation of reactive oxygen species (ROS) [55] (Fig. 2a). Thiamine and benfotiamine exert antioxidant properties, reducing enhanced ROS production in high glucose conditions by normalizing the four metabolic pathways described above [56, 57] (Fig. 2b). Thiamine addition also increases the oxidation of pyruvate to acetyl-CoA, thus counteracting the accumulation of pyruvate and lactate in the cytoplasm [58]. Excess accumulation of these metabolites due to thiamine deficiency may also increase hypoxia-inducible factor-1 $\alpha(\mathrm{HIF}-1 \alpha)$ and, consequently, vascular endothelial growth factor (VEGF) expression, thus worsening diabetic retinopathy [59].

In addition to their antioxidant action, we demonstrated that thiamine and benfotiamine prevent cell damage and apoptosis induced by high glucose in retinal microvascular cells $[8,54,57,60,61]$, and reduce glycation of basement membrane proteins, potentially preventing the detachment of pericytes from retinal capillary wall $[62,63]$. In diabetic rats, benfotiamine prevented experimental retinopathy by inhibiting the formation of acellular capillaries [56]. Oversupplementation of thiamine and benfotiamine averted nephropathy in rats with streptozotocin-induced diabetes, inhibiting the development of microalbuminuria [64], dyslipidaemia, and advanced glycation of plasma proteins [65].

Dysregulation of thiamine transport inside cells may also play a role in thiamine deficiency and related disorders. High glucose induces downregulation of THTR1, THTR2 and their transcription factor $\mathrm{Sp} 1$, in human kidney proximal tubular epithelium [66]. Two single nucleotide polymorphisms located in the SLC19A3 gene encoding for THTR2 may be associated with protection from diabetic retinopathy and nephropathy in type 1 diabetic subjects with long disease duration [67]. Subsequent work in vitro demonstrated that reduced thiamine availability concurs with high glucose in impairing thiamine transport inside both retinal and renal cells involved in diabetic microangiopathy, THTR2 being primarily involved $[61,68]$.

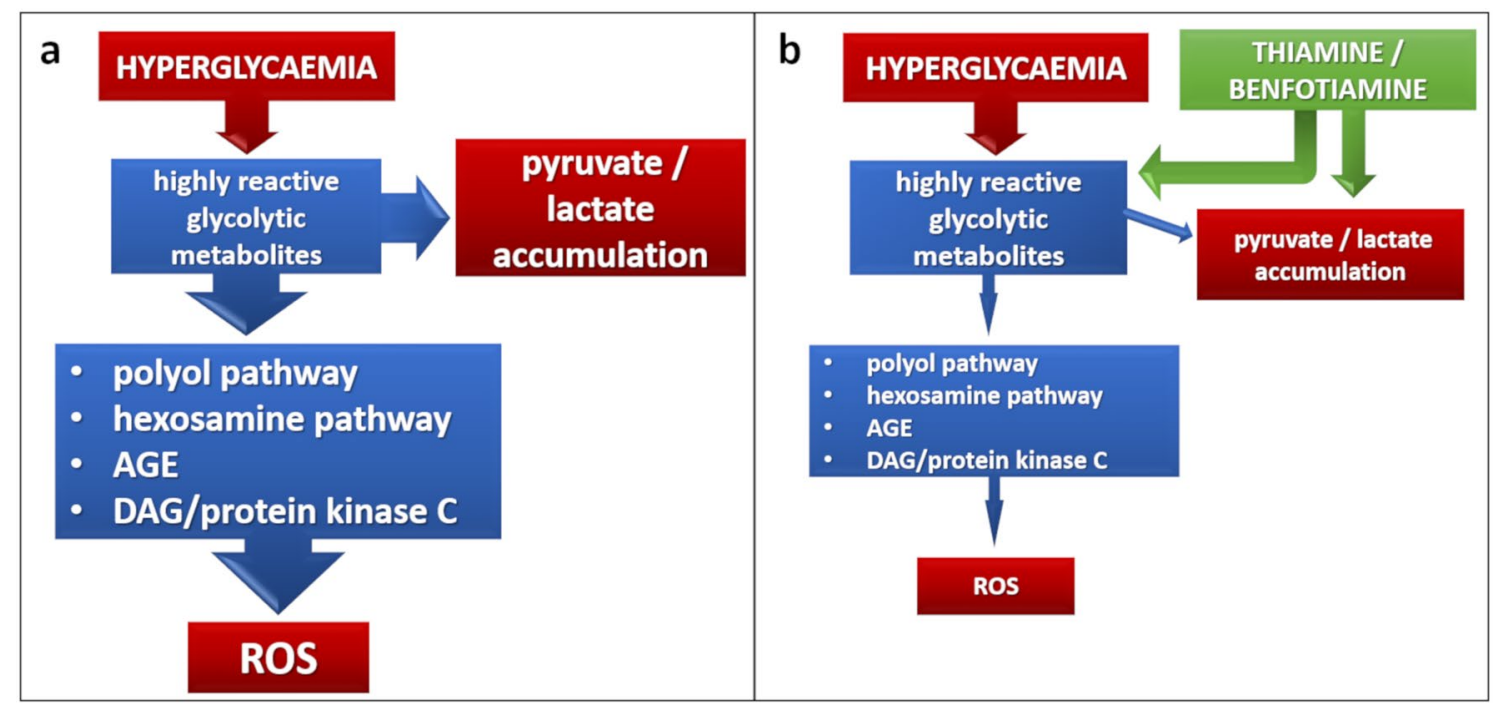

Fig. 2 Mechanisms of action of thiamine as an antioxidant. a The "unifying mechanism" of ROS production according to Nishikawa et al. (2000): increased glycolytic flux due to excess glucose accelerates the four metabolic pathways of high-glucose damage: polyol pathway, hexosamine pathway, AGE production, and de novo synthesis of protein kinase $\mathrm{C}$, leading to ROS accumulation. b Thiamine and benfotiamine normalize all these pathways in the presence of excess glucose, leading to reduced synthesis of $\operatorname{ROS}[56,57]$ 
A few pilot studies in humans reported beneficial effects of thiamine administration on diabetic nephropathy. Type 2 diabetic patients with early stage nephropathy experienced reduction of urinary albumin excretion after three months of thiamine supplementation [69], while benfotiamine had fewer promising effects [70]. Despite all promising proofsof-concept, the potential of thiamine in counteracting development or progression of retinopathy in human diabetes has not been addressed until now, possibly because of the necessity of running large, prolonged trials with sophisticated approaches to grade microangiopathy, especially retinal lesions.

\section{Old drugs and the impenetrable wall of evidence-based medicine}

Over the last 80 years, a relevant amount of work in vitro and animal models has strongly suggested that thiamine supplementation may exert beneficial effects on the pathologic mechanisms of diabetes and its complications. Few studies in limited numbers of patients appear to confirm these observations. Most studies conclude by stressing the need for large structured clinical trials to test this vitamin as a potential and inexpensive option to prevent or slow down the progression of diabetes and its complications. However, these wishes have never materialized. One problem with the tenets of evidence-based medicine is that, apart from its undeniable advantages, it requires the completion of proper RCTs to gain registration for new indications. This approach is rightly reserved for new molecules, where the enormous investments for their development are justified by the prospect of higher returns. Although fully appropriate to leave old-fashioned practices behind and identify adverse effects, this effectively blocks the way to new indications for old medicines [71], including thiamine and its derivatives. An RCT to test their activity in diabetic complications would require the enrollment of thousands of patients, at least 4-year follow-up and sophisticated methods to centrally assess retinopathy, nephropathy, and neuropathy. As thiamine is non-patentable and inexpensive, it will be immensely difficult to raise the funds to run such trials. Even drugs that were subjected to proper RCTs may not make it: fenofibrate, a lipid-lowering agent, repeatedly reduced progression of retinopathy in a clinically significant way [72, 73] and candesartan, an angiotensin receptor blocker, prevented its onset $[74,75]$ but, as these were not pre-specified primary endpoints, neither gained the indication. The conundrum is that, in the general interest of evidence and safety, we may be depriving diabetic people of possible means to ameliorate their condition.
Funding Open access funding provided by Università degli Studi di Torino within the CRUI-CARE Agreement.

\section{Declarations}

Conflict of interest EB and AM have received honoraria from Wörwag Pharma for the preparation of a mini-review on biofactors in diabetes. MP was a member of the Steering Committee of the DIRECT studies on Candesartan in diabetic retinopathy, sponsored by Astra Zeneca.

Ethical approval This manuscript does not include human or animal studies for which ethics approval is required.

Informed consent No human procedure for which an informed consent is required was performed for the writing of this paper.

Open Access This article is licensed under a Creative Commons Attribution 4.0 International License, which permits use, sharing, adaptation, distribution and reproduction in any medium or format, as long as you give appropriate credit to the original author(s) and the source, provide a link to the Creative Commons licence, and indicate if changes were made. The images or other third party material in this article are included in the article's Creative Commons licence, unless indicated otherwise in a credit line to the material. If material is not included in the article's Creative Commons licence and your intended use is not permitted by statutory regulation or exceeds the permitted use, you will need to obtain permission directly from the copyright holder. To view a copy of this licence, visit http://creativecommons.org/licenses/by/4.0/.

\section{References}

1. Funk C (1922) The etiology of the deficiency diseases. Beri-beri, polyneuritis in birds, epidemic dropsy, scurvy, experimental scurvy in animals, infantile scurvy, ship beri-beri, pellagra. In: Funk C (ed) The vitamines. Williams and Wilkins, Baltimore, pp 341-368

2. Bose JP (1949) The role of vitamin B1 in the treatment of diabetes. Ind Med Gaz 83(12):554-556

3. Jansen B, Donath W (1926) The Isolation of Anti-Beriberi Vitamin. Geneeskundig Tijdschrift voor Nederlandsch-Indie (Med J Dutch East Indies) 66:1-2

4. Bender DA (1999) Optimum nutrition: thiamin, biotin and pantothenate. Proc Nutr Soc 58:427-433. https://doi.org/10.1017/s0029 665199000567

5. Frank RA, Leeper FJ, Luisi BF (2007) Structure, mechanism and catalytic duality of thiamine-dependent enzymes. Cell Mol Life Sci 64(7-8):892-905. https://doi.org/10.1007/s00018-007-6423-5

6. Harper C (1979) Wernickes encephalopathy a more common disease than realised a neuropathological study of 51 cases. J Neurol Neurosurg Psychiatry 42(3):226-231. https://doi.org/10.1136/ jnnp.42.3.226

7. Thomson AD (2000) Mechanisms of vitamin deficiency in chronic alcohol misusers and the development of the Wernicke-Korsakoff syndrome. Alcohol Alcohol Suppl 35(1):2-7. https://doi.org/10. 1093/alcalc/35.supplement_1.2

8. Beltramo E, Berrone E, Tarallo S, Porta M (2008) Effects of thiamine and benfotiamine on intracellular glucose metabolism and relevance in the prevention of diabetic complications. Acta Diabetol 45(3):131-141. https://doi.org/10.1007/s00592-008-0042-y 
9. Hoyumpa AM, Strickland R, Sheehan JJ, Yarborough G, Nichols S (1982) Dual system of intestinal thiamine transport in humans. J Lab Clin Med 99(5):701-708

10. Rindi G, Laforenza U (2000) Thiamine intestinal transport and related issues: recent aspects. Proc Soc Exp Biol Med 224(4):246255. https://doi.org/10.1046/j.1525-1373.2000.22428.x

11. Viana MB, Carvalho RI (1978) Thiamine-responsive megaloblastic anemia, sensorineural deafness, and diabetes mellitus: A new syndrome? J Pediatr 93(2):235-238. https://doi.org/10.1016/ s0022-3476(78)80503-4

12. Neufeld EJ, Fleming JC, Tartaglini E, Steinkamp MP (2001) Thiamine-responsive megaloblastic anemia syndrome: a disorder of high-affinity thiamine transport. Blood Cells Mol Dis 27(1):135138. https://doi.org/10.1006/bcmd.2000.0356

13. Ozand PT, Gascon GG, Al Essa M et al (1998) Biotin-responsive basal ganglia disease: a novel entity. Brain 121(Pt 7):1267-1279. https://doi.org/10.1093/brain/121.7.1267

14. Kono S, Miyajima H, Yoshida K, Togawa A, Shirakawa K, Suzuki $\mathrm{H}$ (2009) Mutations in a thiamine-transporter gene and Wernicke's-like encephalopathy. N Engl J Med 360(17):1792-1794. https://doi.org/10.1056/NEJMc0809100

15. Fujiwara M, Sasakawa S, Itokawa Y, Ikeda K (1964) Affinity Of thiamine propyl disulfide-S35 To organs. J Vitaminol (Kyoto) 10:79-87. https://doi.org/10.5925/jnsv1954.10.79

16. Loew D (1996) Pharmacokinetics of thiamine derivatives especially of benfotiamine. Int J Clin Pharmacol Ther 34(2):47-50

17. Schreeb KH, Freudenthaler S, Vormfelde SV, Gundert-Remy U, Gleiter CH (1997) Comparative bioavailability of two vitamin B1 preparations: benfotiamine and thiamine mononitrate. Eur J Clin Pharmacol 52(4):319-320

18. Janes RG, Brady JM (1947) Thiamine deficiency in adult normal and diabetic rats as studied under paired-feeding conditions. Fed Proc 6(1 Pt 2): 136

19. Goodhart R, Sinclair H (1940) Deficiency of vitamin b1 in man as determined by the blood cocarboxylase. J Biol Chem 132(1):1121. https://doi.org/10.1016/S0021-9258(18)73390-5

20. Bracco $F(1940)$ Novità e progressi della farmacoterapia e farmaceutica. Annuario Merck 54:14

21. Siliprandi N, Navazio F (1952) The action of insulin on blood cocarboxylase in diabetes mellitus. Acta Med Scand 142(2):147-148

22. Markees S, Fw M (1949) Therapy of the coma diabeticum with cocarboxylase. Schweiz Med Wochenschr 79(39):931-936

23. Aubertin E (1950) Cocarboxylase treatment of diabetic coma. J Med Bord 127(11):763-764

24. Boulin R, Meyer F, Gueniot M, Lapresle C (1951) Cocarboxylase therapy of diabetic coma. Paris Med 14(10):129-131

25. Alslev J (1953) Treatment of diabetic coma with cocarboxylase. Arztl Wochensch 8(23):540-543

26. von Marken LV, Florijn E (1955) Treatment of diabetic coma with thiamine pyrophosphate. Acta Med Scand 152(4):259-269. https://doi.org/10.1111/j.0954-6820.1955.tb03486.x

27. Siliprandi N, Traverso R (1950) Therapeutic use of di- and triphosphoric esters of thiamine in diabetes mellitus. Farmaco Sci Tec 5(6):655-664

28. Villano F, D'Onofrio F (1953) Therapeutic mechanism of cocarboxylase in diabetes mellitus in relation to the citric acid cycle. Riforma Med 67(44):1213-1219

29. Saito N, Kimura M, Kuchiba A, Itokawa Y (1987) Blood thiamine levels in outpatients with diabetes mellitus. J Nutr Sci Vitaminol 33(6):421-430. https://doi.org/10.3177/jnsv.33.421

30. Tamai H (1999) Diabetes and vitamin levels. Nihon Rinsho 57(10):2362-2365

31. Jermendy G (2006) Evaluating thiamine deficiency in patients with diabetes. Diab Vasc Dis Res 3(2):120-121. https://doi.org/ $10.3132 /$ dvdr.2006.014
32. Thornalley PJ, Babaei-Jadidi R, Al Ali H et al (2007) High prevalence of low plasma thiamine concentration in diabetes linked to a marker of vascular disease. Diabetologia 50(10):2164-2170. https://doi.org/10.1007/s00125-007-0771-4

33. Vindedzis SA, Stanton KG, Sherriff JL, Dhaliwal SS (2008) Thiamine deficiency in diabetes-Is diet relevant? Diab Vasc Dis Res 5(3):215. https://doi.org/10.3132/dvdr.2008.035

34. Valerio G, Franzese A, Poggi V, Patrini C, Laforenza U, Tenore A (1999) Lipophilic thiamine treatment in long-standing insulin-dependent diabetes mellitus. Acta Diabetol 36(1-2):73-76. https://doi.org/10.1007/s005920050148

35. Arora S, Lidor A, Abularrage CJ et al (2006) Thiamine (vitamin B1) improves endothelium-dependent vasodilatation in the presence of hyperglycemia. Ann Vasc Surg 20(5):653-658. https://doi. org/10.1007/s10016-006-9055-6

36. Stirban A, Negrean M, Stratmann B et al (2006) Benfotiamine prevents macro- and microvascular endothelial dysfunction and oxidative stress following a meal rich in advanced glycation end products in individuals with type 2 diabetes. Diabetes Care 29(9):2064-2071. https://doi.org/10.2337/dc06-0531

37. González-Ortiz M, Martínez-Abundis E, Robles-Cervantes JA, Ramírez-Ramírez V, Ramos-Zavala MG (2011) Effect of thiamine administration on metabolic profile, cytokines and inflammatory markers in drug-naïve patients with type 2 diabetes. Eur J Nutr 50(2):145-149. https://doi.org/10.1007/s00394-010-0123-x

38. Alaei Shahmiri F, Soares MJ, Zhao Y, Sherriff J (2013) Highdose thiamine supplementation improves glucose tolerance in hyperglycemic individuals: a randomized, double-blind crossover trial. Eur J Nutr 52(7):1821-1824. https://doi.org/10.1007/ s00394-013-0534-6

39. Alaei-Shahmiri F, Soares MJ, Zhao Y, Sherriff J (2015) The impact of thiamine supplementation on blood pressure, serum lipids and C-reactive protein in individuals with hyperglycemia: a randomised, double-blind cross-over trial. Diabetes Metab Syndr 9(4):213-217. https://doi.org/10.1016/j.dsx.2015.04.014

40. Bartáková V, Pleskačová A, Kuricová K et al (2016) Dysfunctional protection against advanced glycation due to thiamine metabolism abnormalities in gestational diabetes. Glycoconj J 33(4):591-598. https://doi.org/10.1007/s10719-016-9688-9

41. Amirani E, Aghadavod E, Shafabakhsh R et al (2020) Antiinflammatory and antioxidative effects of thiamin supplements in patients with gestational diabetes mellitus. J Matern Fetal Neonatal Med. https://doi.org/10.1080/14767058.2020.1779212

42. Bu L, Smith HA (2018) Forgotten disease: illnesses transformed in chinese medicine. J Hist Med All Sci 73(4):508-510. https:// doi.org/10.1093/jhmas/jry029

43. Eijkman C (1990) Polyneuritis in chickens, or the origins of vitamin research (originally published 1890-1896 in the Geneeskundig Tijdschrift voor Nederlandsch-Indie). Hoffman-La Roche, Basel

44. Hopkins FG (1912) Feeding experiments illustrating the importance of accessory factors in normal dietaries. J Physiol 44(56):425-460. https://doi.org/10.1113/jphysiol.1912.sp001524

45. Shuman CR, Gilpin SF (1954) Diabetic neuropathy: controlled therapeutic trials. Am J Med Sci 227(6):612-617. https://doi.org/ 10.1097/00000441-195406000-00003

46. Whitsell LJ (1962) Neurologic complications of diabetes. Calif Med 96:14-20

47. Stracke H, Lindemann A, Federlin K (1996) A benfotiaminevitamin B combination in treatment of diabetic polyneuropathy. Exp Clin Endocrinol Diabetes 104(4):311-316. https://doi.org/10. 1055/s-0029-1211460

48. Simeonov S, Pavlova M, Mitkov M, Mincheva L, Troev D (1997) Therapeutic efficacy of "Milgamma" in patients with painful diabetic neuropathy. Folia Med 39(4):5-10 
49. Abbas ZG, Swai AB (1997) Evaluation of the efficacy of thiamine and pyridoxine in the treatment of symptomatic diabetic peripheral neuropathy. East Afr Med J 74(12):803-808

50. Winkler G, Pál B, Nagybéganyi E, Ory I, Porochnavec M, Kempler P (1999) Effectiveness of different benfotiamine dosage regimens in the treatment of painful diabetic neuropathy. Arzneimittelforschung 49(3):220-224. https://doi.org/10.1055/s-00311300405

51. Haupt E, Ledermann H, Köpcke W (2005) Benfotiamine in the treatment of diabetic polyneuropathy-a three-week randomized, controlled pilot study (BEDIP study). Int J Clin Pharmacol Ther 43(2):71-77. https://doi.org/10.5414/cpp43071

52. Stracke H, Gaus W, Achenbach U, Federlin K, Bretzel RG (2008) Benfotiamine in diabetic polyneuropathy (BENDIP): results of a randomised, double blind, placebo-controlled clinical study. Exp Clin Endocrinol Diabetes 116(10):600-605. https://doi.org/10. 1055/s-2008-1065351

53. Stirban A, Pop A, Tschoepe D (2013) A randomized, doubleblind, crossover, placebo-controlled trial of 6 weeks benfotiamine treatment on postprandial vascular function and variables of autonomic nerve function in Type 2 diabetes. Diabet Med 30(10):1204-1208. https://doi.org/10.1111/dme.12240

54. La Selva M, Beltramo E, Pagnozzi F et al (1996) Thiamine corrects delayed replication and decreases production of lactate and advanced glycation end-products in bovine retinal and human umbilical vein endothelial cells cultured under high glucose conditions. Diabetologia 39(11):1263-1268. https://doi.org/10.1007/ s001250050568

55. Nishikawa T, Edelstein D, Brownlee M (2000) The missing link: a single unifying mechanism for diabetic complications. Kidney Int Suppl 77:S26-30. https://doi.org/10.1046/j.1523-1755.2000. 07705.x

56. Hammes HP, Du X, Edelstein D et al (2003) Benfotiamine blocks three major pathways of hyperglycemic damage and prevents experimental diabetic retinopathy. Nat Med 9(3):294-299. https:// doi.org/10.1038/nm834

57. Berrone E, Beltramo E, Solimine C, Ape AU, Porta M (2006) Regulation of intracellular glucose and polyol pathway by thiamine and benfotiamine in vascular cells cultured in high glucose. J Biol Chem 281(14):9307-9313. https://doi.org/10.1074/jbc. M600418200

58. Mk H, Kreisler O (1949) The determination of early thiaminedeficient states by estimation of blood lactic and pyruvic acids after glucose administration and exercise. J Nutr 37(4):411-427. https://doi.org/10.1093/jn/37.4.411

59. Zera K, Zastre J (2018) Stabilization of the hypoxia-inducible transcription factor- 1 alpha $(\mathrm{HIF}-1 \alpha)$ in thiamine deficiency is mediated by pyruvate accumulation. Toxicol Appl Pharmacol 355:180-188. https://doi.org/10.1016/j.taap.2018.07.004

60. Beltramo E, Berrone E, Tarallo S, Porta M (2009) Different apoptotic responses of human and bovine pericytes to fluctuating glucose levels and protective role of thiamine. Diabetes Metab Res Rev 25(6):566-576. https://doi.org/10.1002/dmrr.996

61. Beltramo E, Mazzeo A, Lopatina T, Trento M, Porta M (2020) Thiamine transporter 2 is involved in high glucose-induced damage and altered thiamine availability in cell models of diabetic retinopathy. Diab Vasc Dis Res 17(1):1479164119878427. https:// doi.org/10.1177/1479164119878427

62. Beltramo E, Pomero F, Allione A, D'Alù F, Ponte E, Porta M (2002) Pericyte adhesion is impaired on extracellular matrix produced by endothelial cells in high hexose concentrations. Diabetologia 45(3):416-419. https://doi.org/10.1007/s00125-001-0761-x

63. Beltramo E, Nizheradze K, Berrone E, Tarallo S, Porta M (2009) Thiamine and benfotiamine prevent apoptosis induced by high glucose-conditioned extracellular matrix in human retinal pericytes. Diabetes Metab Res Rev 25(7):647-656. https://doi.org/ 10.1002/dmrr.1008

64. Babaei-Jadidi R, Karachalias N, Ahmed N, Battah S, Thornalley PJ (2003) Prevention of incipient diabetic nephropathy by highdose thiamine and benfotiamine. Diabetes 52(8):2110-2120. https://doi.org/10.2337/diabetes.52.8.2110

65. Karachalias N, Babaei-Jadidi R, Kupich C, Ahmed N, Thornalley PJ (2005) High-dose thiamine therapy counters dyslipidemia and advanced glycation of plasma protein in streptozotocin-induced diabetic rats. Ann N Y Acad Sci 1043:777-783. https://doi.org/ 10.1196/annals.1333.090

66. Larkin JR, Zhang F, Godfrey L et al (2012) Glucose-induced down regulation of thiamine transporters in the kidney proximal tubular epithelium produces thiamine insufficiency in diabetes. PLoS ONE 7(12):e53175. https://doi.org/10.1371/journal.pone.00531 75

67. Porta M, Toppila I, Sandholm N et al (2016) Variation in SLC19A3 and protection from microvascular damage in type 1 diabetes. Diabetes 65(4):1022-1030. https://doi.org/10.2337/ db15-1247

68. Mazzeo A, Barutta F, Bellucci L et al (2021) Reduced thiamine availability and hyperglycemia impair thiamine transport in renal glomerular cells through modulation of thiamine transporter 2 . Biomedicines 9(4):385. https://doi.org/10.3390/biomedicines904 0385

69. Rabbani N, Alam SS, Riaz S et al (2009) High-dose thiamine therapy for patients with type 2 diabetes and microalbuminuria: a randomised, double-blind placebo-controlled pilot study. Diabetologia 52(2):208-212. https://doi.org/10.1007/s00125-008-1224-4

70. Alkhalaf A, Klooster A, van Oeveren W et al (2010) A doubleblind, randomized, placebo-controlled clinical trial on benfotiamine treatment in patients with diabetic nephropathy. Diabetes Care 33(7):1598-1601. https://doi.org/10.2337/dc09-2241

71. Porta M (2003) Evidence b(i)ased medicine. CRAP may be sounding timely alarm. BMJ 326:602. https://doi.org/10.1136/bmj.326. 7389.602

72. Keech A, Simes RJ, Barter P et al (2005) Effects of long-term fenofibrate therapy on cardiovascular events in 9795 people with type 2 diabetes mellitus (the FIELD study): randomised controlled trial. Lancet 366(9500):1849-1861. https://doi.org/10.1016/ S0140-6736(05)67667-2

73. Chew EY, Ambrosius WT, Davis MD et al (2010) Effects of medical therapies on retinopathy progression in type 2 diabetes. $\mathrm{N}$ Engl J Med 363(3):233-244. https://doi.org/10.1056/NEJMoa1001288

74. Chaturvedi N, Porta M, Klein R et al (2008) Effect of candesartan on prevention (DIRECT-Prevent 1) and progression (DIRECTProtect 1) of retinopathy in type 1 diabetes: randomised, placebocontrolled trials. Lancet 372(9647):1394-1402. https://doi.org/10. 1016/S0140-6736(08)61412-9

75. Sjølie AK, Klein R, Porta M et al (2008) Effect of candesartan on progression and regression of retinopathy in type 2 diabetes (DIRECT-Protect 2): a randomised placebo-controlled trial. Lancet 372(9647):1385-1393. https://doi.org/10.1016/S01406736(08)61411-7

Publisher's Note Springer Nature remains neutral with regard to jurisdictional claims in published maps and institutional affiliations. 